Open Access

\title{
Guest editorial foreword for the special issue on automated software testing: trends and evidence
}

\author{
Andre Takeshi Endo ${ }^{*}$, Antonia Bertolino², José Carlos Maldonado ${ }^{3}$ and Márcio Eduardo Delamaro ${ }^{3}$
}

\author{
* Correspondence: \\ andreendo@utfpr.edu.br \\ ${ }^{1}$ Universidade Tecnologica Federal \\ do Parana (UTFPR), Cornelio \\ Procopio, Brazil \\ Full list of author information is \\ available at the end of the article
}

Society and industry are increasingly dependent on software. Software-supported environments can be critical, pervasive, persistent, mobile, distributed, real-time, context-aware, and adaptive. Thus, a growing need emerges for fast and rigorous approaches to develop and evolve these systems. This drives, among others, the research for techniques, criteria and supporting tools for software testing.

Systematic and automated approaches have shown capable of reducing the overwhelming cost of engineering such systems. Industrial success cases have been openly reported and academic interest continues to grow as observed by the increasing number of researchers in the field. While there exist various trends on evolving the automation in software testing, the provision of sound empirical evidence is still needed on such area. It is our pleasure to open this special issue of the Journal of Software Engineering Research and Development that focuses on research trends on automated software testing, as well as empirical evidence on such approaches. We received six submissions, which underwent a rigorous review process for quality and relevance. Only two papers (i.e. $33 \%$ ) have passed this selection.

The first paper, "An algorithm for combinatorial interaction testing: definitions and rigorous evaluations" by Juliana Marino Balera and Valdivino Alexandre Santiago Júnior, introduces a greedy algorithm for unconstrained combinatorial interaction testing. Two versions of the algorithm are compared in the first experiment. The second experiment compares the best version with five other algorithms found in the literature. The results gave evidence that the proposed algorithm is the best option for higher strengths. This work is an invited extension of the best paper nominated in the 1st Brazilian Symposium on Systematic and Automated Software Testing (SAST), held on 19-20 September 2016, in Maringá, Brazil.

The second paper, "Similarity testing for role-based access control systems" by Carlos Diego Nascimento Damasceno, Paulo Cesar Masiero, and Adenilso Simao, proposes an approach for similarity testing of Role-Based Access Control (RBAC) systems. The authors compare the proposed approach with simple similarity and random prioritization using the APFD metric. The results gave evidence that the RBAC similarity is generally more effective than the compared techniques.

The guest editors would like to thank the many people who contributed to the successful organization of this special issue. First, we appreciate the effort spent by the

(c) The Author(s). 2018 Open Access This article is distributed under the terms of the Creative Commons Attribution 4.0 International License (http://creativecommons.org/licenses/by/4.0/), which permits unrestricted use, distribution, and reproduction in any medium, provided you give appropriate credit to the original author(s) and the source, provide a link to the Creative Commons license, and indicate if changes were made. 
authors who submitted excellent papers to this special issue. We also show our gratitude to the reviewers for their dedication, expertise, and competent feedback. Last but not least, the JSERD editors-in-chief, Alessandro Garcia, Claudia Verner, and André van der Hoek, provided expert guidance throughout the process.

Author details

'Universidade Tecnologica Federal do Parana (UTFPR), Cornelio Procopio, Brazil. ${ }^{2}$ ISTI - Istituto di Scienza e Tecnologie dell'Informazione A.Faedo, Pisa, Italy. ${ }^{3}$ Universidade de São Paulo (USP), São Carlos, Brazil.

Received: 30 January 2018 Accepted: 30 January 2018

Published online: 05 February 2018

Submit your manuscript to a SpringerOpen ${ }^{\odot}$ journal and benefit from:

- Convenient online submission

- Rigorous peer review

- Open access: articles freely available online

- High visibility within the field

- Retaining the copyright to your article

Submit your next manuscript at $>$ springeropen.com 